\title{
Research and Practice on Professional Teaching Pattern of Environmental Engineering that Highlight Engineering View
}

\author{
Yunfen Shi ${ }^{\mathrm{a}}$, Changming $\mathrm{Pan}^{\mathrm{b}}$, Zhenye Zhang $^{\mathrm{c}}$ and Meitong $\mathrm{Jin}^{\mathrm{d}}$ \\ School of Chemical engineering, Northeast Electric Power University, Jilin, 132012 \\ ashiyunfen0220@163.com, bpang171746441@qq.com, c1106989110@qq.com, \\ d842820664@qq.com
}

\section{Keywords: Environmental sciences; Engineering capability; Research; Practice}

\begin{abstract}
Aiming at training talents with engineering capability for environment major, propose establishing a comprehensive cultivating system that have curriculum groups and a practice teaching system with engineering background under the guidance of foster plan on building the connotation of engineering capability and keep forging a teaching team of high quality as well as innovating the traditional teaching and testing patterns as ensuring measures.

The follow-up research on previous students who have post shows that: students need a long period before they adapt to the actual work which means a fairly low start, a poor operational ability and poorer capability to solve actual problems appeared in projects, in order to reverse this circumstance, we highlight engineering opinion in all respects in our teaching and emphasize ability training.
\end{abstract}

\section{Build a Foster Plan on the Connotation of Engineering Capability}

Optimize the structure of the class, form curriculum groups, the curriculum groups that the foster plan wants to build, normally each group have two or three courses in the same direction, some courses are guiding courses, belongs to basic professional courses in each directions step by step according to the time, so students will gradually form up logic thinking mode of how to start their work when they study these courses [1].For example, water pollution control is a professional direction in environmental engineering, so this course is surely central course of this direction teaching inherent features and application range of all technologies in dealing with polluted water, the features of structures in sewage pool, design method as well as equipment selection. In order to do this, we newly increased basic environment engineering design and environmental civil engineering as our courses, these courses form up a curriculum group together with water pollution control, so no matter students work in designing institutes or enterprises, they will have a global view on starting or running programs, get into the role more quickly, carry out the design construction operation and management work carefully and logically. [2]

Optimize the practice link, linking theory with practice, the environment major in the school I am teaching in has a practice teaching system including the combination of experiment courses production practice, practice training social practice and graduation projects increase the period of practicing and decrease classroom teaching, let students study in practicing, improve in applying, link theory with practice, intensify and practice engineering capability taught in class further, consolidate and intensify professional quality further, improve engineering ability in practice. In experiment courses, get rid of the experiments that have less background of engineering, increase comprehensive and design experiments that linked closely with engineering. Contact and strengthen the development of practice base through a variety of methods, choose representative enterprises as practice base, provide students with feasible, quickly and efficiently place of practicing [3]. Set up reasonable internship contents during practice time, finish the goal that everybody go and everybody know. During the process of practice, combine teaching contents naturally with what students practice, keep representative programs as the background of practice training, bring students' subjective initiative into play on practice training. 


\section{Set up Engineering Content Syllabus}

The syllabus is programmatic document of education, divided into teaching syllabus and practice syllabus, the content of courses must be linked up effectively, form up an organic whole with the main line of projects. The practice syllabus should be compiled with a close link to the teaching syllabus whereas it needs to highlight engineering background, training the ability of doing projects. For example, The experiment of determining the organic matter soil has been changed into determining heavy metal in the soil around Jilin Yuan power plant, through the reform, enhance the practical applicability, extend students' awareness in soil pollution caused by waste residue poured by industrial and mining enterprises, prepare for teaching the migrate and transfer of heavy metal in environmental science, also pave the way for students Who want to do environmental quality monitoring works.[6]

\section{Form up Training Platform of Engineering Ability}

Recommend students to join in laboratory open program, college students' innovation and entrepreneurship training plan program, college students' challenger cup and join into scientific research developing platform of teachers' scientific researches, set up training mechanism and regulatory mechanism for training students' engineering capability effectively These platforms usually work when students are at second semester of grade three, and each platform will have corresponding tutor. Laboratory open up program is freedom grouped by students and declare to school under the guidance of tutors, the program usually has a strong practical topic as background, has a wide range, but the essence is to develop students' engineering capability, including how to begin the work independently, overall planning the process of work, how to gain the expected result, how to break through the difficulties of the program The program of college students' innovation and entrepreneurship training plan also have tutor to provide guidance and declare to school or the provincial education department. The school I am teaching in has mechanism for college students' challenge cup, not only highlight the efficiency, but also provide most of students with a training chance. Teachers' science researches platform is open to students, absorb and encourage students to take part in science researches, usually start with the basic skill training and gradually widen students' vision let students have acquaintance with preceding issue of science and technology fields. As a result of taking part in teachers' scientific researches many students make full use of their vacation time, it also have a crucial influence on improving students' engineering capability.[4]

\section{Build up Institutionalized Teaching Team with Engineering Capability}

Teaching team is the implementer of training plan and also direct trainer of students' engineering capability. It is supposed to advance the improvement of teachers' engineering capability actively at aspect of school, set up a number of training and cultivating platforms, and institutionalized it. The school I am teaching in have set up platforms such as competition of teachers' engineering capability, teachers' enterprises practice, school's scientific funding and start funding, teaching match prize of education result and education quality fully arouse the enthusiasm of teachers [5].At aspect of talent introduction, cheek the quality strictly, recruit high quality talents with engineering background or have been trained first. These platforms form up a whole system and linked up with. Professional title evaluation which form a whole institution, improve the whole quality-oriented teaching team. Teachers' enterprises practice has a strong characteristic [8].School require teachers to take part in enterprises practice before professional title evaluation, demand at least three months experience of enterprises practice in one or two years, and arrange experts to make assessment of defense. During this process, teacher get more contact with enterprise, get more acquaintance with practical problems, get a combination of knowledge and practice, Improve quality obviously, build up the bridge between enterprises and school form the circumstances that school becomes development base of enterprises' technology, enterprises become frontier of school. 


\section{Reform Traditional Educational and Examinational Patterns}

The class taught mainly by methodology, in its class teaching not only need to teach student theoretical knowledge systematically, ut also need to teach them means to solve actual problems, therefore, regard methodology on working out engineering issues as main line in teaching is especially important. For example, in teaching calculation of resistance loss of fluidic turbulent flow in circular tube. On account of the large number of influence factors, the complex problem is unable to use there tical method to get the derivation of resistance formula for calculating [7].Then use dimensional analysis can deal with this actual problem well. Pay attention to explaining profound theories in simple language during the class, the examples should be appropriate, vivid, closely link to students' lives, and combine the content with what students practice. The examples should be linked up with the actual production, professional related or have been seen in work. For example, When finished teaching Bernoulli equation in the fluid flow, and start teaching the calculation of pipeline, present the example like how to make sure the users don't influence each other when the water pipe and gas pipe is working together; how to find blocking point when you discover industrial water pipe is limited. In order to deepen students understand of what they have learned. Only in this way, students will feel class, appropriate vivid and easily understand, build a stronger foundation for solving actual problems unconsciously.

Reform the traditional cramming education and only final exams mood, fully arise students' interest in study, offer guarantee for engineering capability training [7].Cramming education is usually used in college courses, reform this boring education pattern, it is supposed to be a pattern that improve students' interest in studying. Carry out more attempts in test methods. Such as mid-term examination, quiz, examination with course work, experiments with test etc. Use a variety of methods to strengthen students' study.

\section{Acknowledgments}

This work was supported in part by grants from the Teaching Reform of Undergraduate Course in Jilin Province Higher Education Documents of Jilin Province No.[2016]32 and Teaching Reform of the Northeast Electric Power University in 2015 (JX201511).

\section{References}

[1] L.H Zhang, Y.P Jia and Y.J Zhang of the Course Reform and Practice of Water Pollution Control Engineering [J]. Journal Of Northeast Electric Power University (in Chinese), Vol. 33 (2013) No.4, p.82

[2] Y.F Shi, X.H Xu and L.D Liu of the Professional Practice Mode on Environmental Engineering with Characteristics of Power Plant Environmental Protection [J]. Journal of Northeast Electric Power University (in Chinese), Vol. 33 (2013) No.4, p.88

[3] Y.J Zhang, H.F Zhang and X.H Sun of the Exploring and Practice to Improve Quality of Graduation Project for Applied Chemistry Speciality [J]. Journal of Northeast Electric Power University (in Chinese), Vol. 33 (2013) No.4, p.97

[4] X.M. Qi, L.B. Zhu, S.J. Xu and D. Sheng of the Practical Ability Training in Course of Remote Sensing Major in Environmental Engineering [J], Science of Surveying and Mapping (in Chinese), Vol. 40 (2015) No.10, p.167

[5] Q. Wei, Y.P. JIA, and S. Zheng, et al of the Biological Technology Comprehensive Experiment' $\mathrm{s}$ Teaching Reform and Practice Based on the Mode of Application Type Innovative Talents Training[J]. Journal Of Northeast Electric Power University (in Chinese), Vol. 33 (2013) No.4, p.91

[6] D.Q. Mo and J.P. Mo of the Study on How to Improve Application Ability of Environment Engineering Majors [J], Journal of Guilin University of Electric Technology (in Chinese), Vol. 
28 (2008) No.4, p.373

[7] Y.G. Li, B. Yan, M.X. Zeng, H.Y. Fu, T. Chai and J.F. Liu of the Construction and Practice of Practical Education System of Applied Environmental Engineering [J], Experiment Science Technology (in Chinese), Vol. 9 (2011) No.3, p.105

[8] Y.Y. Lu, S.G. Liu, Y.P. Hu and L. Xia of the Study on Constructing Practical Teaching System of Environmental Engineering [J], Experimental Technology and Management (in Chinese), Vol. 29 (2012) No.10, p.169 